\title{
The use of combined-blast is the main way to improve the energy efficiency of blast furnaces
}

\author{
N. Spirin ${ }^{1}$, V. Shvidkiy ${ }^{1}$, Y. Yaroshenko ${ }^{1} \&$ Y. Gordon ${ }^{2}$ \\ ${ }^{I}$ Department of Metallurgy, Ural Federal University, Russia \\ ${ }^{2}$ Department of Metallurgy, HATCH, Canada
}

\begin{abstract}
The world production of hot metal and pig iron in 2012 reached 1.3 billion tons. More than 500 million tons of metallurgical coke produced from 650 million tons of expensive coking coals was consumed in blast furnaces to achieve this production goal. Metallurgical coke is a major contributor to the production costs of hot metal and pig iron, typically making up to $48-52 \%$ of the hot metal operating cost. Because of this, the reduction in metallurgical coke consumption was always a major goal for blast furnace operators. Supplemental fuels, especially in the form of a combined blast, are typically used to reduce coke consumption in a blast furnace. The major types of combined blast and supplemental fuels are as follows: oxygen enrichment, natural gas, oil and pulverized coal injection. The replacement coefficients of coke by these supplement fuels depend on the fuel quality, the arrangement of the injection process and adjustments in the blast furnace operating practice to optimize heat and mass transfer processes, metallic yield, gas dynamics and material movement. The fundamentals of the blast furnace process to achieve a highly efficient operation of the blast furnace with combined blast are discussed in this paper. The methodology of this research and development work is based on the theory of heat transfer in a blast furnace combined with local and overall heat and mass balances, the analysis of temperature distribution and material and gas movement. As a result, the maximum achievable replacement coefficients and reduction in the operating cost of hot metal were estimated alongside the required adjustments in blast furnace operation.

Keywords: blast furnace, combined blast, heat transfer, principles of injection fuel.
\end{abstract}




\section{Introduction}

The principles and results of the modernization of blast furnace operation are commonly accepted and very well known. The highest furnace productivity (up to $3.5-4 \mathrm{thm} / \mathrm{m} 3 /$ day), the amount of injected hydrocarbons (up to $240 \mathrm{~kg}$ PCI per ton of hot metal and $220 \mathrm{Nm}^{3}$ of natural gas per ton of hot metal), oxygen enrichment of up to $14-15 \%$, blast temperature of up to $1300^{\circ} \mathrm{C}$ and the lowest coke rate (below 270-280 kg/thm) were achieved at the end of the last and beginning of the $21^{\text {st }}$ centuries. The achievement of these parameters of blast furnace operation was stipulated by the following:

- usage of fluxed sinter and pellets with the high content of total iron - above 59-61\%;

- addition of DRI or HBI into blast furnace burden;

- usage of supplemental fuels such as pulverized coal (PC), natural gas (NG) or oil;

- possibility to preheat blast up to $1250-1300^{\circ} \mathrm{C}$;

- implementation of bell-less charging devices, allowing much better control the burden distribution;

- development and implementation of computer based control and management information systems to maintain stable blast furnace parameters;

- operation of blast furnace on stable acid slag with following de-sulphurization of hot metal in a separate De-S station before BOF steelmaking (reduction in sulphur below $0.02-0.04 \%$ );

- application of high quality refractories and efficient cooling systems including copper staves and plates.

The analysis of hot metal production cost at Iron \& Steel Works of Russian Federation revealed that metallic burden and burden additives contribute about $50 \%$ of the hot metal production cost, while coke and natural gas contribution is about $40 \%$. In addition the coke cost accounts for more than $90 \%$ of the total fuel cost. Thus, reduction in coke consumption plays the major role in reduction of hot metal production cost. This generally is achieved by improvements in a metallic burden and coke quality, replacement of coke by supplemental fuel, increase in blast temperature and oxygen enrichment etc. All of these were demonstrated by results of blast furnaces operation during the last decades. The quality of metallic burden also is extremely important. However, reduction in metallic burden consumption mainly is a function of the content of total iron, which generally depends on technologies and operating practices employed by mining-beneficiation plants and less on blast furnace proper.

\section{Fundamentals of the heat transfer theory in the blast furnace}

Practically all physicochemical processes occurring in a blast furnace are pyrometallurgical. Hence their development depends on the amount of heat generated in the furnace raceway, and temperature distribution in the furnace volume. This relationship is complicated by the fact that the development of heat 
transfer processes which determine the temperature distribution are affected by the chemical processes which alter not only the composition and physical state of the burden components but also their mass. Thus, the phenomena of heat and mass transfer are interrelated and this determines the approach to the analysis of the blast furnace process.

The mathematical model describing thermophysical and physicochemical phenomena of the blast-furnace smelting was proposed by Kitaev [1] in 1944. A complete description of the model is given in the monographs [2-5]. Kitaev considered the blast furnace as a counter-current flow heat exchanger where thermal and mass transfer processes proceed simultaneously. He found that the temperature distribution in a blast furnace was determined by the ratio of heat capacities of the burden and gas flows $-\mathrm{W}_{\mathrm{b}}$, and gas $\mathrm{W}_{\mathrm{g}}(\mathrm{kJ} / \mathrm{h} \mathrm{deg})$, which are equal to the product of the flow rate of the burden $G_{b}(\mathrm{~kg} / \mathrm{h})$ or gas $V_{g}\left(\mathrm{~m}^{3} / \mathrm{h}\right)$ to the specific heat of the substance of this flow $c_{b}\left(\mathrm{~kJ} / \mathrm{kg}\right.$ degree) or $\mathrm{c}_{\mathrm{g}}\left(\mathrm{kJ} / \mathrm{m}^{3} \mathrm{deg}\right)$, that is:

$$
\mathrm{W}_{\mathrm{b}}=\mathrm{G}_{\mathrm{b}} \mathrm{c}_{\mathrm{b}} \text { or } \mathrm{W}_{\mathrm{g}}=\mathrm{V}_{\mathrm{g}} \mathrm{c}_{\mathrm{g}} .
$$

To account for the thermal effects of exothermic or endothermic reactions, Kitaev introduced the concept of "apparent specific heat" $-c_{\text {app }}$, and suggested a formula for its estimation:

$$
\mathrm{c}_{\mathrm{app}}=\mathrm{c}_{\mathrm{b}}+\left( \pm \mathrm{c}_{\mathrm{ch}}\right) .
$$

The first term in this expression $c_{b}$ is the physical specific heat, and the second $\left( \pm \mathrm{c}_{\mathrm{ch}}\right)$ is a "chemical" one. The apparent specific heat considers the sources and sinks of heat in the course of the mass-exchange processes.

Depending on dimensions of the material and gas flows and thermal properties of their components either mass or volumetric "apparent" specific heat can be used to calculate the temperature fields in the blast furnace. As was mentioned above the ratio of the burden flow heat capacities $\mathrm{W}_{\mathrm{b}}$, to the gas flow heat capacity $\mathrm{W}_{\mathrm{g}}$ is the determining factor in the analysis of heat exchange processes in a blast furnace. This ratio $-\mathrm{W}_{\mathrm{b}} / \mathrm{W}_{\mathrm{g}}=\mathrm{m}$, can take values of $\mathrm{m}<1.0, \mathrm{~m}>1.0$ and $\mathrm{m}=1.0$. Thus, the value of $\mathrm{m}$ determines the difference in the nature of the temperature fields over the height of the burden column. Analysis of the change in " $\mathrm{m}$ " value along the blast furnace height allowed Kitaev to pioneer thermophysical specifics of blast furnace operation:

(i) Heat capacity of the gases flow practically doesn't change over the height of the blast furnace since its decrease as the gas cools is compensated by the increase in the volume of gas flow components with higher heat capacity, as the result of the reduction of iron ore, evaporation of moisture and other factors;

(ii) Heat capacity of the burden flow $\mathrm{W}_{\mathrm{b}}$ is more complex. Its change is connected with the chemistry of the blast furnace operation and temperature. With the heating of the burden in the upper part of blast furnace and release of heat during indirect reduction processes the value of $\mathrm{W}_{\mathrm{b}}$ increases. The ratio $\mathrm{W}_{\mathrm{b}} / \mathrm{W}_{\mathrm{g}}$ in this area of a blast furnace is estimated by Kitaev as $0.8-0.9$. In the 
blast furnace lower parts, the physical processes of burden melting and melt overheating are accompanied by the processes of direct reduction, the development of which requires a considerable amount of heat. These and other endothermic processes increase the ratio $\mathrm{W}_{\mathrm{b}} / \mathrm{W}_{\mathrm{g}}$ for the bottom part of the blast furnace. Depending on the hot metal (pig iron) grade the value of $\mathrm{m}=\mathrm{W}_{\mathrm{b}} / \mathrm{W}_{\mathrm{g}}$ increases and fluctuates between 2.0 and 3.0. The distribution of the gas and burden flow heat capacities over the height of blast furnace is shown in Fig. 1(a).

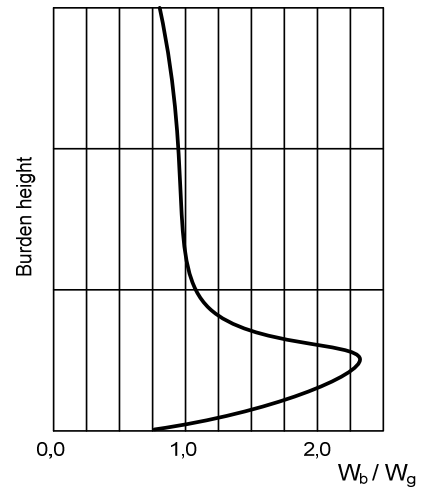

(a)

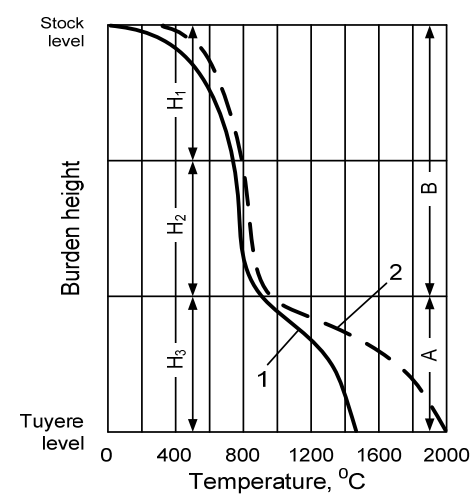

(b)

Figure 1: Distribution of $\mathrm{m}=\mathrm{W}_{\mathrm{b}} / \mathrm{W}_{\mathrm{g}}$ (a) and material and gas temperatures (b) along blast furnace height. $\mathrm{A}$ - direct reduction; $\mathrm{B}$ - indirect reduction; $\mathrm{H}_{1}-$ upper zone of heat exchange; $\mathrm{H}_{2}$ - moderated (reserve) temperature zone; $\mathrm{H}_{3}$ - lower zone of heat exchange.

Results of Figure 1(a) show that for the upper zone of blast furnace $\mathrm{W}_{\mathrm{b}}<\mathrm{W}_{\mathrm{g}}$ and $\mathrm{m}<1.0$. For the bottom zone $-\mathrm{W}_{\mathrm{b}}>\mathrm{W}_{\mathrm{g}}$ and $\mathrm{m}>1.0$. The maximum of the direct reduction processes development corresponds to the maximum of the heat consumption and consequently to the largest value of the burden flow heat capacity. As the burden descends, the development of the direct reduction processes is weakened due to the decrease of unreduced iron. As a consequence, the heat capacity of the burden flow begins to decrease. Depending on the hot metal grade, the heat capacity of the burden flow at the tuyeres level can be very close to the heat capacity of the gas stream, and sometimes the condition may occur when $\mathrm{W}_{\mathrm{b}}<\mathrm{W}_{\mathrm{g}}$, which is shown in Fig. 1(a)

Analysis of Figure 1(b) results leads to the following conclusions:

- At the upper heat transfer zone of blast furnace $-\mathrm{H}_{1}, \mathrm{~W}_{\mathrm{b}}<\mathrm{W}_{\mathrm{g}}$. In these conditions the gas flow enthalpy always is greater than the burden can absorb. Excessive heat is carried by the gas through the furnace top and the burden reaches gas temperature practically $5-8 \mathrm{~m}$ below the stock line;

- At the bottom heat transfer zone of blast furnace $-\mathrm{H}_{3}, \mathrm{~W}_{\mathrm{b}}>\mathrm{W}_{\mathrm{g}}$. Because of this the burden cannot be heated to the gas temperature in the raceway. The temperature of the burden is lower than the initial gas temperature. Thus, within the bottom heat transfer zone, as burden descends, the difference in 
gas and material temperatures increases and reaches a maximum at the tuyeres zone. This zone of heat exchange is characterized by high values of heat transfer coefficients, significantly developed surface of heat exchange due to metallic burden melting and slag formation and development of a highly endothermic Boudouard reaction $-\mathrm{C}+\mathrm{CO}_{2}=2 \mathrm{CO}$. In these conditions a relatively small height of the material column is sufficient for the gas-burden thermal energy exchange. At the exit of the bottom zone of heat transfer zone $\mathrm{H}_{3}$, the gas and burden temperatures are practically equal.

- In the middle part of the blast furnace (zone of moderated temperature $\mathrm{H}_{2}$ ) $\mathrm{W}_{\mathrm{b}} \approx \mathrm{W}_{\mathrm{g}}$. At the exit of the heat transfer upper zone $\mathrm{H}_{1}$, the burden is heated almost to the temperature of the gas. Because of this the rate of heat exchange practically reduced to zero.

Kitaev characterized the heat transfer in the blast furnace scheme described above by the following features [1] (quotation):

1. Heat transfer in blast furnace is accomplished in two successive steps, separated by a reserve zone of variable height.

2. The thermal operation of each zone is independent, except that the temperature of the gas reaching the upper zone is dependent on the temperature of the gas leaving the lower zone.

3. Heat transfer in a blast furnace is complete, as is indicated by the presence of "a reserve or moderated temperature zone".

The analysis of numerous studies of intensive operation of blast furnace in modern conditions with the usage of combined blast (high levels of natural gas, pulverized coal and oxygen injection) confirms that the regularities of heat exchange in blast furnace developed by Kitaev remain unchanged and they are extremely important to maintain the process stability and blast furnace performance [6].

\section{Principles (conditions) of blast furnaces operation with the combined blast}

The theory of heat transfer in a blast furnace was being successfully evolved especially during the development of the blast furnace operation using the combined blast. The operation of blast furnaces in such conditions showed:

- injection of natural gas leads to the reduction in coke rate;

- oxygen enrichment of the blast with simultaneous natural gas injection ensures an increase in blast furnaces productivity;

- all above contribute to the reduction in the hot metal cost;

- additional opportunities for control of blast furnace appeared.

Usage of natural gas and oxygen stipulated significant changes in heat and mass transfer, melting, gas dynamics, combustion processes in the furnace raceway, which significantly affects blast furnace performance and requires further development of theory of heat exchange in blast furnace. The initial studies of blast furnaces operation with natural gas injection showed the reduction in RAFT (raceway adiabatic flame temperature) and increase in the hearth gas volume. These phenomena alter the ratio of thermal capacities of 
burden and gas flows over the height of a blast furnace and thus affect the heat transfer scheme. Hydrogen enrichment of hearth gas leads to the increase in rate of indirect reduction with corresponding decrease in the rate of direct reduction, reducing the heat demand in the bottom zone of blast furnace. The increase of hydrogen concentration in hearth gas leads to the decrease of the gas density, improving the gas-dynamics of the blast furnace. On the other hand, the reduction in coke rate and the increase in the volume of the hearth gas makes the gas-dynamic conditions less favorable.

For this new conditions of blast furnace operation Kitaev together with his associates, defined the basic principles which must adhere during the injection of any supplemental fuels and oxygen in combined blast through the tuyeres: "Any additives to the blast, as a minimum, must ensure the retention of the temperature distribution over the blast furnace height and therefore the burden reduction conditions".

This principle requires maintaining the following conditions:

1. The thermal conditions and heat transfer in the low heat transfer zone of blast furnace should always guarantee a standard quality of hot metal. In other words the thermal energy released during coke and hydrocarbons combustion must compensate the amount of heat consumed for burden heating from the temperature of the "zone of moderate temperatures" to the final temperature of hot metal and slag, taking into account melting, direct reduction of iron, silicon, manganese, phosphorus and other elements, as well as the processes of hot metal and slag formation. This heat amount is determined by the hearth gas generation per tone of hot metal and raceway temperature;

2. The reduction potential of hearth gas in the low heat transfer zone had to be maintained the same or even increased above prior injection level;

3. The thermal conversion of hydrocarbons of supplemented fuels to $\mathrm{CO}$ and $\mathrm{H}_{2}$ in the enriched by oxygen, should be completed within the furnace raceway without carbon soot formation;

4. The temperature distribution within the upper heat transfer zone must be maintained at the optimal level to support required extend of iron oxides indirect reduction. The burden flow heat capacity in this part of the blast furnace should be less than the gas flow heat capacity, i.e. $\mathrm{W}_{\mathrm{b}}<\mathrm{W}_{\mathrm{g}}$;

5. The gas-dynamic conditions in the material column should be balanced without loss of blast furnace productivity. Selection of the "supplemental fuel-oxygen" ratio, improvement in the gas-dynamic characteristics of the raw material and optimization of their distribution in furnace cross-section, as well as the increase in top gas pressure allow this condition to be fulfilled.

Each of these conditions can become a limiting factor. It all depends on blast furnace conditions, burden column permeability, burden reducibility and other factors. For example, if there is no heat reserve in the upper heat exchange zone the fourth condition, with the injection of supplemental fuel, will be a limiting factor. This means that the ratio of the burden and gas flow heat capacities in the new conditions of the blast furnace operation $(\mathrm{m} ")$ exceeds the value of $\left(\mathrm{m}^{\prime}\right)$, which determined the operation of the blast furnace before start of injection: $\mathrm{m}^{\prime \prime}>\mathrm{m}^{\prime}$ or $\left(\mathrm{W}_{\mathrm{b}} / \mathrm{W}_{\mathrm{g}}\right)^{\prime \prime}>\left(\mathrm{W}_{\mathrm{b}} / \mathrm{W}_{\mathrm{g}}\right)^{\prime}$. 
If, however, there is a heat excess in the heat balance of the upper heat transfer zone after start of injection of supplemental fuel, $(\mathrm{m}$ ") becomes lower than $\left(\mathrm{m}^{\prime}\right)$ and the thermal operation the upper heat transfer zone will not be a limiting factor for operation of blast furnace. This approach to the analysis of the influence of supplemental fuels and oxygen injection on blast furnace performance was verified by practice.

\section{Characteristics of hydrocarbon additives (supplemental fuels)}

The quality of supplemental fuel should be assessed according to the weight ratio of carbon and hydrogen content $-\mathrm{C} / \mathrm{H}$. For natural gas this ratio is equal to $\mathrm{C} / \mathrm{H} \approx 3$; for fuel oil, which is used in the blast furnace process, $\mathrm{C} / \mathrm{H} \approx 8.0$; and for pulverized coal it is more than 14 . Such considerable change in $\mathrm{C} / \mathrm{H}$ values indicates that with replacement of natural gas by pulverized coal the fraction of hydrogen in the products of incomplete combustion is reduced.

The volume of products of incomplete combustion $\left(\mathrm{CO}+\mathrm{H}_{2}\right)$ of one $\mathrm{kg}$ of supplemental fuel also depends on the $\mathrm{C} / \mathrm{H}$ ratio. $\mathrm{CO}$ and $\mathrm{H}_{2}\left(\mathrm{~m}^{3} / \mathrm{kg}\right)$ output data for these conditions verifies this conclusion:

$\begin{array}{lllc} & \mathrm{CO} & \mathrm{H}_{2} & \Sigma \mathrm{CO}+\mathrm{H}_{2} \\ \text { natural gas } & 1.40 & 2.80 & 4.20 \\ \text { fuel oil } & 1.61 & 1.27 & 2.88 \\ \text { coal dust } & 1.32 & 0.61 & 1.93 \\ \text { coke } & 1.59 & 0.22 & 1.81\end{array}$

Thus, when the $\mathrm{C} / \mathrm{H}$ ratio in tuyere gas increases, hydrogen concentration and tuyere gas generation are reduced. Thermal effects of incomplete combustion reactions are also important indicators.

\subsection{Natural gas}

Natural gas has characteristics which determined its application to the blastfurnace process. They include:

(i) gas purity regarding to sulfur content and other impurities;

(ii) ability to increase the concentration of $\mathrm{H}_{2}$ in the hearth gas;

(iii) simple and inexpensive technique of natural gas distribution through tuyeres and its injection into each tuyere;

(iv) straightforward control of the natural gas rate;

(v) possibility of preheating before injection into the tuyeres.

The injection of natural gas is followed by a reduction in slag output, sulphur and phosphorus levels due to a decrease of specific coke consumption. 


\subsection{Fuel oil}

Fuel oil which is often used as the supplemental fuel is characterized by the following features:

(i) low ash content and relatively low sulphur content;

(ii) higher thermal effect of incomplete combustion in comparison with natural gas;

(iii) storage and preparation of fuel oil for combustion needs special facilities;

(iv) fuel oil should be warmed up to reduce its viscosity;

(v) incomplete combustion of fuel oil without formation of carbon soot requires an adequate pulverization and uniform distribution of fuel oil droplets over the tuyere with the help of special nozzles;

(vi) fuel oil rate adjustment at each tuyere of the blast furnace is possible.

The use of fuel oil with low ash content reduces slag volume due to a decrease in the coke rate.

\subsection{Pulverized coal (PC)}

Pulverized coal as supplemental fuel is characterized by the following features:

(i) high ash content;

(ii) higher content of sulfur in comparison with natural gas and fuel oil;

(iii) much higher thermal effect of incomplete combustion;

(iv) storing and preparing of coal for combustion (averaging of composition, grinding, removal of moisture etc.), transportation of pulverized coal to tuyeres, require special and expensive equipment;

(v) complete gasification of coal particles in the raceway is achieved only with a particular size of particles.

These features defined the following requirements to pulverized coal:

- Low ash content determines the coke replacement coefficient, slag output, and silicon content in hot metal. Ash content of PCI must not exceed ash content of coke. Recommended ash content is $10-12 \%$. The quality of ash determines the PC injection rate: higher ash basicity allows higher rates of PC injection.

- Melting point of ash has to be higher than $1,400^{\circ} \mathrm{C}$.

- Content of sulfur should be lower than $1 \%$ and must not exceed the content of this component in coke.

- Content of volatile matter (VM) in coal should be around $30-40 \%$. Such coal provides quick and complete combustion of coal particles in the tuyere zone, increases hydrogen concentration in the hearth gas and reduces coke rate.

- Good PC grindability reduces the consumption of electrical energy for pulverization, transport and distribution of fuel at tuyeres. The best results are achieved with PC particle sizes from 50-80 microns.

- Coals with high content of VM are characterized by low sulfur content and are easy available around the globe. The low cost of such coals makes them attractive for use as the supplemental fuel.

The degree of pulverized coal utilization un blast furnace depends on the quality of mixing of PC and oxygen, heating, ignition and combustion of the coal 
particles. The main factor which determines the PC combustion process is the initial size of a PC particle. The pulverized-coal particle combustion process in the tuyere zone has been investigated at Ural Federal University. The developed mathematical model [6] takes into account the phenomena of the coal particle heating to the ignition temperature, hygroscopic and hydrate moisture evaporation, thermal decomposition of coal and combustion of volatiles as well as the phenomena of oxygen transport to the front of the coal oxidation reactions and the removal of combustion reactions products. Numerical analysis of the coal particle combustion process was performed for a PC particle with a size of 100 microns, with a different content of volatiles (38.7\% and 5.64\%, by mass), and various rates of PC injection (from $275-480 \mathrm{~kg} / \mathrm{t}$ of hot metal). It was assumed that pulverized coal was injected against the flow at a distance of $0.8 \mathrm{~m}$ from the tuyere tip. This provided the opportunity for the heating of the coal particles in the blast flow before entering into the raceway's combustion zone. The results of this work, showed in Fig. 2, lead to the following conclusions:

- The degree of coal particle burning largely depends on the content of volatiles in the fuel: more volatiles in coals - more completely particle burn;

- The impact of the PC injection rate on the degree of particles burn-up is ambiguous: it is significant for coals with a high content of volatiles and almost delete for coals with low content of volatiles;

- The influence of point of pulverized coal injection into tuyere is important for fuel with low content of volatile matter and unimportant for coals with high content of volatile matter. Combustion of gasification products promotes faster heating of fuel particles up to the ignition temperature and the development of the solid residue (soot) burning process. Thus, injection of PC should be made at a distance of 500-700 $\mathrm{mm}$ from the tuyere tip.

Knowledge of the injected fuels properties and requirements for their injection into the tuyere are the basis for creation of favorable conditions for PC injection in order to reduce coke rate and production cost of hot metal.

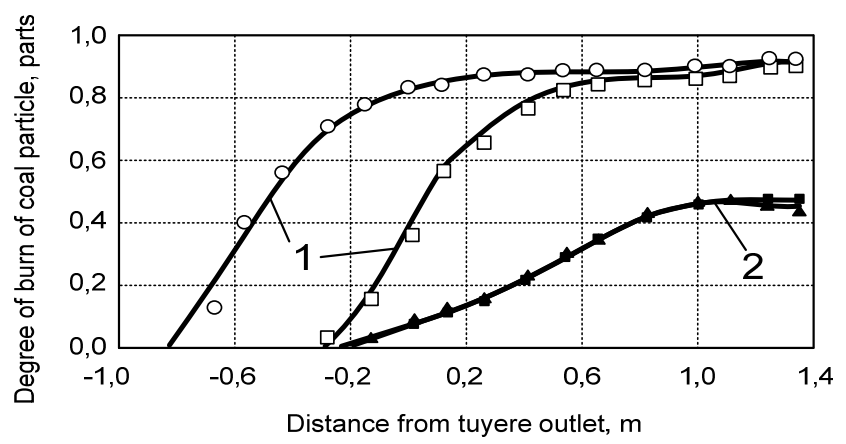

Figure 2: The degree of burn of coal particle $0.1 \mathrm{~mm}$ diameter: the amount of pulverized coal fuel at tuyere $(\mathrm{kg} / \mathrm{hr}): \bigcirc 275 ; \square 320 ; \boldsymbol{\Delta} 340$;

- 480; volatile matter coal ( $\%$ mass): $1-\mathrm{V}_{\mathrm{v}}=38.7 ; 2-\mathrm{V}_{\mathrm{v}}=5.64$. 


\section{Blast furnaces operation with the combined blast}

The experience of blast furnaces operation with the combined blast permitted the formulation of the following principles:

- Heat input into the low heat transfer zone decreases due to the injection of cold fuel additives and incomplete combustion of the injected fuels [6]. This heat can be recovered by an increase in the blast rate and injected fuels temperatures as well as an increase in the oxygen content in the blast.

- When natural gas consumption increases, transient processes have a sign-variable nature that is caused by the inertia less effect of temperature change in the hearth and the inertial effect of counter-current intensity change [5]. If, at the initial moment of time, the hearth temperature reduces due to an increase in heat demand for the natural gas decomposition, and causes a reduction of silicon content in hot metal, then after the time of one materials turn-over, the blast furnace starts to warm up and silicon content increases. This silicon increase is connected to the increase in the degree of indirect reduction and the decrease in the degree of direct reduction of iron due to an increase of hydrogen content and rising temperatures in the upper heat exchange zone. The latter is caused by the increase of hearth gas generation and the decrease of burden's descending velocity.

- Deterioration of the burden gas permeability due to the reduction of coke consumption and increase of the hearth gas generation can cause the increase of a pressure drop between the tuyeres and the blast furnace top. To maintain and in most cases raise, the productivity of blast furnaces, the well-known methods of blast furnace operation control are used: increase of oxygen content in the blast; magnification of the blast kinetic energy at tuyeres zones; and redistribution of ore load along the radius of the furnace. By influencing these options, and the injected fuel flow rate, it always possible to create conditions for more effective performance of blast furnace in terms of coke rate and productivity.

The results of investigation of blast furnaces operation with the combined blast identified energy efficiency techniques justified by the coke replacement coefficient $\mathrm{K}_{\mathrm{c}}$. This coefficient is equal to the ratio of saved coke $\Delta \mathrm{K}, \mathrm{kg} / \mathrm{t}$ of pig iron to the amount of injected fuel $-K_{f}$. For natural gas $K_{f}$ is measured in $\mathrm{m}^{3} / \mathrm{t}$ of hot metal, and for fuel oil and PC in $\mathrm{kg} / \mathrm{t}$ hot metal. Fig. 3 shows the values of coke replacement coefficients $K_{c}=\Delta K / K_{f}$ for various supplemental fuels. Currently natural gas and pulverized coal are the most widely used supplemental fuels for blast furnace process. Fuel oil is also used in some blast furnaces. The choice of injected fuel is determined mainly by the fuel price and expenses involved in its preparation and injection into a blast furnace, as well as reduction in the production cost of hot metal and productivity increase.

Significant reduction in coke rate at the high level of supplemental fuels injection will require [7] the following:

- improvement of the metallic burden strength to prevent burden deterioration;

- maintain the coke strength after reaction (CSR) at a level of $65-70 \%$ and coke reactive index, CRI, of a level below 20-23\%; 
- increase in the metallurgical properties of iron ore;

- heating of the blast up to $1,300^{\circ} \mathrm{C}$ and beyond;

- oxygen enrichment into the blast to control RAFT, hearth gas generation, and intensity of melting;

- usage of tuyeres of special design to maintain the conditions for complete gasification of hydrocarbon additives within the tuyere zone;

- raising gas pressure at the blast furnace top for increasing the blast flow rate when the pressure drop is maintained;

- maintain satisfactory distribution of materials and gases by means of bellless top.

The theory of heat exchange and the principles of supplemental fuel injection into the blast furnace recently have been utilized to develop strategy of supplemental fuel distribution in the group of blast furnaces. Developed economic-mathematical models allowed optimization of the supplemental fuel injection rate and oxygen enrichment as to the group of blast furnaces as well as to the individual one in order to gain maximum benefits from the use of the combined blast. These models take into account the changes in the amounts of resources allocated to a blast-furnace plant, the change in the conditions and raw materials parameters of individual blast furnace operations, the situation with one or more blast furnace shut-downs, and other technological situations. The usage of the developed model in the modern blast furnace control system allow to solve many complicated problems of blast furnace operation and improve the impact of the decisions made by technicians-and-engineers with respect to the changes in the volume of fuel and energy resources, instability of the composition and quality of smelting iron ore and market conditions on furnace performance [8].

The development of hot metal production strategy and Iron and Steel Works expansion for any company is primarily determined by the demand of steel in the domestic and foreign markets. The raw materials and coals availability for

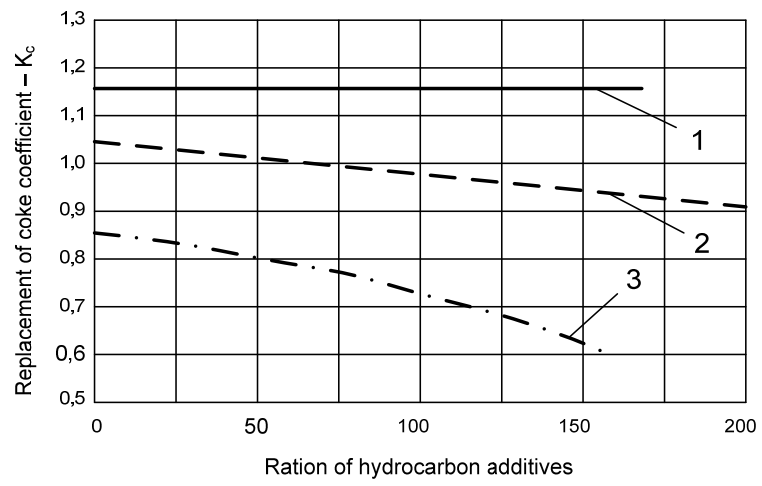

Figure 3: The dependence of the replacement coefficient $\left(\mathrm{K}_{\mathrm{c}}\right)$, on the amount of injected fuel: 1 - fuel oil, $\mathrm{kg} / \mathrm{t}$ iron; 2 - pulverized coal, $\mathrm{kg} / \mathrm{t}$ iron; 3 - natural gas, $\mathrm{m}^{3} / \mathrm{t}$ iron. 
production of hot metal also play an important role. The winning strategy could be determined by combination of the market analysis, selection of the efficient production technologies (including blast furnace operation) and sorrow economic evaluation of the Iron and Steel Works [9].

\section{Conclusions}

1. The major principles of blast furnace operation with supplemental fuels and combined wind are formulated based on theory of heat exchange in the blast furnace developed by Kitaev and his associates.

2. The energy efficiency of blast furnace operation depends on the compliance of operating parameters to the developed principles of combined wind, Reduction in coke rate by 90,175 and $210 \mathrm{~kg} / \mathrm{thm}$ with injection of natural gas, fuel oil and pulverized coal, respectively, was predicted and confirmed by actual operating results.

\section{References}

[1] Kitaev, B.I., The schema of heat exchange in the blast furnace and the preparation of ores for melting, Steel, 7-8, pp. 15-18, 1944.

[2] Kitaev B.I., État actual de la théorie des échanges thermiques dans le haut fourneau. Journ. Intern. de Siderurgie, eds. J.G. Iarochenko \& B.L. Lazarev, Luxemburg, pp. 1-11, 1962.

[3] Kitaev, B.I., Yaroshenko, Yu.G., Suchkov, V.D., Heat exchange in shaft furnaces. Translated from the Russian by M.M. Page and B.Simons and ed. by Young. Pergamon Press: London, UK, p. 299, 1967.

[4] Kitaev, B.I., Yaroshenko, Yu.G., Sukhanov, E.L., Ovchinnikov, Yu.N, Shvydky, V.S., Heat engineering of the blast furnace process, Metallurgiya: Moscow, p. 248, 1978.

[5] Spirin, N.A., Ovchinnikov, Yu.N., Shvydky, V.S., Yaroshenko, Yu.G., Heat-exchange and increasing the efficiency of blast-furnace smelting, USTU: Ekaterinburg, p. 243, 1995.

[6] Yaroshenko, Yu.G., Gordon, Ya.M., Khodorovskaya, I.Yu., Energy-efficient and resource-saving technologies of ferrous metallurgy, JSC "BASE": Ekaterinburg, p. 670, 2012.

[7] Savchuk, N.A., Kurunov, I.Ph., Blast-furnace production on the eve of the XXI century, OJSC “Chermetinformation”: Moscow, p. 42, 2000.

[8] Spirin, N.A., Lavrov, V.V., Rybolovlev, V.V., et al. The model decision support systems in automated process control systems for blast-furnace production, UrFU: Ekaterinburg, p. 462, 2010.

[9] Gordon, Ya.M., Freizlikh, M., Els, Zh. The choice of production technology of pig iron and iron according to the specific conditions of the enterprise. Blast-furnace production - XXI century. Int. Cong. of furnacemen, "Codex": Moscow, pp. 506-518, 2010. 